\title{
Educação da infância - estar junto sem ser igual Conflitos e alternativas da relação da educação infantil com o ensino fundamental!
}

\section{Education in Childhood - being together and being unique}

\section{Conflicts and alternatives concerning the relationship between children's education and elementary education!}

\author{
Gizele de Souza *
}

\begin{abstract}
RESUMO
O texto que ora se apresenta propõe discutir a especificidade da educação infantil na relação com o ensino fundamental, etapas constitutivas da educação básica segundo a Lei de Diretrizes e Bases da Educação Nacional n. 9394/96 em vigor. $O$ propósito recai na problematização da intricada relação entre educação infantil e ensino fundamental, a partir do olhar de pesquisadora da educação infantil e no intuito de demarcar as particularidades dessa área de pertencimento e identificar um fio condutor, um elo de articulação no trabalho com o ensino fundamental que preserve as peculiaridades, trajetórias e identidade de cada etapa educativa (educação infantil e ensino fundamental). A bibliografia especializada na educação infantil é utilizada como fonte, bem como compõem a base empírica, dados estatísticos fruto de uma pesquisa, em andamento, coordenada pela Universidade Federal do Paraná, com dados de

* Professora do setor de Educação da Universidade Federal do Paraná, professora da PósGraduação em Educação na mesma universidade e coordenadora do Núcleo de Estudos e Pesquisas sobre Infância e Educação Infantil (NEPIE).E-mail: nepie@ufpr.br).
\end{abstract}


violações de direitos da criança e do adolescente registrados por Conselhos Tutelares de 36 municípios que incluem Curitiba e Região Metropolitana, Vale do Ribeira e Litoral do Paraná. Um dos elos entre a educação infantil e o ensino fundamental defendido no texto é a constituição de um projeto de formação humana, formação para a emancipação das crianças e dos adultos que nesses espaços atuam.

Palavras-chave: Educação Infantil; Ensino Fundamental; educação da infância; especificidade da educação infantil.

\begin{abstract}
The aim of this text is to discuss the specifics of children's education in relation to elementary education in determinative stages of basic education according to the current Law of Directives and Basis of National Education Number 9394/96. The purpose of this study is to examine the problems arising from the complex relationship of children's education and elementary education from the research viewpoint of children's education in order to map the particularities of this field and identify how they connect and link with elementary education that preserves the peculiarities, pathways and identities of each stage of education (children's education and elementary education). The literature on children's education is utilized as a source and also constitutes an empirical basis and statistical data, which are the fruit of an ongoing research coordinated by the Federal University of Paraná State, with data concerning violations of the rights of children and adolescents registered by Conselhos Tutelares (Brazilian Human Rights Commissions). Taking place in thirty-six cities and towns including Curitiba and its surrounding Metropolitan Region, Vale do Ribeira and the towns that lie along the coastal regions. One of the links between children's education and elementary education in the text is the establishment of a humane project to emancipate children and adults from the conditions in which they currently find themselves.

Key words: children's education, elementary education, education in childhood, specifics of children's education.
\end{abstract}

Em 1907, o estado do Paraná aprovara um Regulamento da Instrução Pública ${ }^{1}$ que previa em texto legal a presença do "ensino infantil" (assim era nomeado) como etapa educacional própria, separada do ensino primário. Previase que o ensino infantil seria ministrado em jardim-de-infância, a partir dos três anos de idade e até no máximo os sete anos. A separação entre o ensino infantil e o ensino primário na estrutura do sistema educacional paranaense oscilou

${ }^{1}$ Estabelecido pelo Decreto n. 479, de 10 de dezembro do mesmo ano. 
em várias legislações no decorrer dos anos do século XX², e em 1909, com o Regulamento Orgânico do Ensino Público do Estado ${ }^{3}$ (o ensino infantil volta a ser incluído como parte do ensino primário), previa-se que o ensino fosse ministrado tendo-se cuidadosamente em vista a idade das crianças, que não permitisse esforço prolongado, donde resultasse qualquer fadiga. As indicações legais aqui trazidas, com marcas histórico-jurídico-educativas próprias da época na qual forem produzidas, têm como finalidade apenas provocar uma reflexão sobre a natureza e especificidade da educação infantil na relação com o ensino fundamental, quando por exemplo o ensino infantil mesmo ocupando o espaço de etapa do ensino primário no Paraná, já dedicava uma atenção às crianças que ali estariam sendo atendidas, desde a questão da sua condição etária até a lógica da rotina, para que essa não provocasse nas crianças, como foi dito, qualquer tipo de fadiga (temática que constituíra uma preocupação dos gestores, políticos e intelectuais da época).

O título do texto traz consigo o que pode ser uma problemática e ao mesmo tempo uma alternativa na relação da educação infantil com o ensino fundamental ${ }^{4}$; ou seja, como a educação infantil compõe com o ensino fundamental e médio o nível da educação básica, estão essas etapas articuladas e encadeadas em um mesmo processo educativo. Esse encadeamento escolar pode ser compreendido como um avanço, como expõe Carlos Roberto Jamil Cury ao argumentar que a idéia de educação básica está ligada ao conceito de base para a cidadania, e que

a própria etimologia do termo base nos confirma esta acepção de conceito e etapas conjugadas sob um só todo. Base provém do grego básis,eós e significa, ao mesmo tempo, pedestal, suporte, fundação e andar, pôr em marcha, avançar. (CURY, 2002, p.171, grifos no original).

Entendo também que esse estar junto (a educação infantil com as outras etapas da educação básica) pode representar, pelo menos no plano de ações de determinadas instituições educativas brasileiras, uma subserviência de uma etapa à outra, especialmente da educação infantil em relação ao ensino fundamental,

\footnotetext{
${ }^{2}$ Para detalhamento sobre a constituição da legislação educacional paranaense no decorrer das duas primeiras décadas do século XX, ver tese de doutoramento de Souza, Gizele de (2004).

${ }^{3}$ Lei n. 894, de 19 de abril, regulamentada pelo Decreto n. 510, de 15 de setembro de 1909.

${ }^{4}$ Etapas da educação básica, configuração dada pela atual Lei de Diretrizes e Bases da Educação - Lei n. 9.394/96.
} 
devido a vários fatores, entre eles, a recente consolidação da identidade da educação infantil no Brasil e o lugar que o ensino fundamental ocupa socialmente.

O que trago para o debate é a intricada relação entre educação infantil e ensino fundamental, a partir do olhar de pesquisadora da educação infantil. Proponho neste texto abordar aspectos dessa relação, no esforço de demarcar as particularidades da área da educação infantil, e identificar um fio condutor, um elo de articulação no trabalho entre essas duas etapas de educação básica. Quando a esse último termo, é importante lembrar que se trata

de um conceito novo, original e amplo em nossa legislação educacional, fruto de muita luta e de muito esforço por parte de educadores que se esmeraram para que determinados anseios se formalizassem em lei. (CURY, 2002, p.171)

\section{Em busca da especificidade da educação infantil: algumas notas históricas}

Colegas da educação vêm demarcando já há algum tempo em suas publicações e em trabalhos de seus grupos de pesquisa a especificidade da educação infantil no contexto da educação brasileira e a necessidade de superação de uma perspectiva "adultocêntrica"; ou seja, sociedade construída e pensada para os adultos ou, como expressa Rosemberg, "na sociedade-centrada-no-adulto a criança não é. Ela é um vir a ser. Sua individualidade deixa de existir. Ela é potencialidade e promessa". (ROSEMBERG, 1985, p.25).

Esse esforço da área de educação infantil em demarcar as finalidades específicas do trabalho com as crianças de zero a seis anos vem de longa data, um movimento constituído de pesquisadores, militantes, gestores e professores, que em determinados momentos encontra menos força na articulação com outras áreas do conhecimento e outros movimentos sociais, e em outros tem-se mostrado mais articulado, seja nos fóruns acadêmicos, nas associações científicas e nos movimentos políticos, tais como o Movimento Interfóruns de Educação Infantil do Brasil (MIEIB) junto às políticas nacionais e regionais de educação infantil 5 .

${ }^{5}$ Para saber mais da história do movimento, ver "Educação Infantil: construindo o presente", publicado em 2002, e o site<http://www.mieib.org.br/> 
O Ministério da Educação publicou em 1994 os Anais do I Simpósio Nacional de Educação Infantil ${ }^{6}$, e entre as recomendações deste ${ }^{7}$ inscreve-se como primeira posição a de que "a criança deve ser o alvo a ser alcançado pelas políticas e ações de Educação Infantil, assim como o critério de validade para qualquer proposta para a área”. (MEC, 1994, p.170). A perspectiva que fora defendida é a de que a criança estava em primeiro plano e não como contexto de fundo para as políticas educacionais e da educação infantil; o reconhecimento de que a criança pequena é cidadã, um ser competente, sofisticado, exigente ,e que a ela devem se voltar propostas e políticas de qualidade.

Uma das questões centrais sobre qualidade na educação infantil que se discutia à época recaía na necessidade de se estabelecerem critérios que orientassem as instituições de educação infantil na garantia dos direitos fundamentais das crianças, ou, como denunciava Fúlvia Rosemberg

a ausência de padrões de qualidade (...) refere-se ao conjunto do sistema público direto ou conveniado de educação infantil, principalmente quando ele se destina ao atendimento de crianças pobres que, em nosso país, são majoritariamente crianças negras. (ROSEMBERG, 1994, p.155)

A temática da qualidade na educação infantil vai ganhando espaço nas investigações brasileiras. Sebastiani (1996), em sua tese de doutoramento "Educação Infantil: o desafio da qualidade - um estudo da rede municipal de creches em Curitiba - 1989 a 1992", elegeu o tema da qualidade dos serviços de educação infantil e utilizou como base metodológica os critérios de qualidade definidos para a Rede para a Infância da Comissão Européia ${ }^{8}$.

Três anos após a denúncia expressa por Rosemberg no Simpósio Nacional de Educação Infantil, sobre a ausência de padrões de qualidade para o sistema público de creches e pré-escolas, o MEC publica "Critérios para um Atendimento em

\footnotetext{
${ }^{6}$ Simpósio promovido pela Secretaria de Educação Fundamental, Departamento de Políticas Educacionais, Coordenação Geral de Educação Infantil (COEDI) e pela Comissão Nacional de Educação Infantil, realizado em Brasília de 8 a 12 de agosto de 1994.

${ }^{7}$ A equipe de relatoria era composta por: Ângela Rabelo Barreto, Carmem Craidy, Fúlvia Rosemberg, Maria Fernanda Rezende Nunes, Rita de Cássia Coelho, Solange Jobim e Souza e Vicente Faleiros.

${ }^{8} \mathrm{O}$ documento intitula-se "La qualità nei servizi per l'infanzia: un documento di discussione, de Irene Balageur, Juan Mestres, Helen Penn, versão italiana (mimeo), 1990.
} 
Creches que Respeite os Direitos Fundamentais das Crianças" (1997) ${ }^{9}$, de autoria de Maria Malta Campos e Fúlvia Rosemberg. Esse documento tornou-se, ao longo dos anos, uma referência clássica para a área porque sistematiza, por meio de doze critérios, um conjunto de compromissos para com as crianças nas instituições de educação infantil, com uma linguagem direta e propositiva, em uma perspectiva que traz o quotidiano e as miudezas do trabalho educativo e da vida das crianças. Avalio que nesse momento se cria um conjunto de critérios que demarca o consenso na educação infantil do que se configura como objetivos peculiares para a área. E, desse modo, vale a pena apontá-los:

- Nossas crianças têm direito à brincadeira;

- Nossas crianças têm direito à atenção individual;

- Nossas crianças têm direito a um ambiente aconchegante, seguro e estimulante;

- Nossas crianças têm direito ao contato com a natureza;

- Nossas crianças têm direito à higiene e à saúde;

- Nossas crianças têm direito a uma alimentação sadia;

- Nossas crianças têm direito a desenvolver sua curiosidade, imaginação e capacidade de expressão;

- Nossas crianças têm direito ao movimento em espaços amplos;

- Nossas crianças têm direito à proteção, ao afeto e à amizade;

- Nossas crianças têm direito a expressar seus sentimentos;

- Nossas crianças têm direito a uma especial atenção durante seu período de adaptação à creche;

${ }^{9}$ A apresentação do documento informa que a primeira versão do texto foi preparada no contexto do projeto de assessoria e formação de profissionais de creche de Belo Horizonte, posteriormente foi discutido no I Simpósio Nacional de Educação Infantil em Brasília, em agosto de 1994, e ao final desse ano contou com o apoio do Ministério de Educação e Desporto, que organizou um encontro de especialistas em São Paulo, para discutir a segunda versão do documento. 
- Nossas crianças têm direito a desenvolver sua identidade cultural, racial e religiosa. (MEC/SEF/COEDI, 1997, p. 11) ${ }^{10}$

A mobilização nacional em prol da infância e da educação infantil, desde os movimentos de mulheres na luta por creches ${ }^{11}$, com a discussão da Assembléia Constituinte e posterior aprovação da Carta Magna de 1988 - que significou "um marco histórico para a redefinição doutrinária e para o lançamento dos princípios de implementação de novas políticas para a infância" (CRAIDY, 1994, p.19), com a promulgação do Estatuto da Criança e do Adolescente (Lei Federal n. 8.069/1990), com os embates e debates em torno do texto da LDB n. 9.394/96 e com as normatizações complementares em âmbito federal, estadual e municipal, repercute não só no fortalecimento político-educativo da educação infantil, como também no incentivo da produção sobre o tema e na busca pela consolidação da identidade da área no campo da educação.

Um exemplo dessa necessidade de incremento e visibilidade na produção científica para a educação infantil se constata no texto de Angela Barreto, que coordenava a educação infantil no Ministério da Educação no início da década de 1990, no qual expunha que uma das recomendações dirigidas ao MEC era a necessidade de estabelecer

intercâmbio estreito com o INEP, CAPES, CNPQ, FINEP e Fundações Estaduais de Amparo à Pesquisa, não só para viabilizar a disseminação do conhecimento produzido na área da educação infantil, mas também para apoiar e fomentar novas pesquisas, inclusive estimulando outras áreas do conhecimento a realizarem estudos relativos à educação da criança pequena, às suas práticas sociais e às políticas a ela direcionadas, bem como a produzirem tecnologia necessária para desenvolvê-las. (BARRETO, 1994, p. 126)

Se, de um lado, pressionava-se o Executivo para criar novas articulações com esferas de fomento à pesquisa na área de educação infantil, outros esfor-

${ }^{10}$ O percurso de atuação e publicações da Coordenação Geral de Educação Infantil, sob a responsabilidade de Angela Barreto no período de 1994 a 1996, até a publicação dos Referenciais Curriculares Nacionais para a Educação Infantil - RCNEI, em 1998, encontra-se no texto "A Educação Infantil: uma questão para o debate”, de Marina Palhares e Cláudia Martinez.

11 Ver texto de Fúlvia Rosemberg "O movimento de mulheres e a abertura política no Brasil: o caso da creche - 1984", 1989. 
ços foram sendo realizados no sentido de compreender melhor a produção já inscrita na área. Um bom exemplo disso é o trabalho de Eloísa Rocha, que se propôs a

investigar as pesquisas que tratam da educação infantil, tendo em vista traçar sua trajetória recente e mapear suas perspectivas para consolidação de um campo particular na área da Educação, qual seja, a Pedagogia da Infância, que por ora e com fins de demarcar os limites de suas fronteiras com uma educação da criança na escola - chamaremos de Pedagogia da Educação Infantil. (ROCHA, 1996, p. 11).

Para dar efetividade ao seu propósito, Rocha (1996) selecionou produções científicas sobre educação infantil apresentadas nos congressos de Psicologia (SBP e SBPC), Antropologia, Sociologia e Ciências Políticas (ANPOCS e SBPC), História (ANPUH e SBPC) e Pedagogia (ANPED e SBPC), no período circunscrito de 1990 a 1996. Destaco breves considerações apresentadas por Rocha a fim de visualizar algumas tendências por ela identificadas no tocante à constituição da educação infantil como um campo com particularidades e identidade. A autora admite que foi possível perceber

o nascimento de uma Pedagogia, com corpo, procedimentos e conceituações próprias. Identifica-se, portanto, uma acumulação de conhecimentos sobre a educação infantil que tem origem em diferentes campos científicos, que além de resultarem em um produto de seu próprio campo, têm resultado em contribuições para a constituição de um campo particular no âmbito da Pedagogia [...] (ROCHA, 1996, p.134)

Ainda com Eloísa, apreende-se que uma pedagogia da infância (expressão cunhada pela autora), embora apenas se coloque como uma possibilidade, sugere que seja possível demarcar, "ainda que necessariamente transitória e provisória, de um campo em constituição", ela avança argumentando que a "possibilidade desta constituição depende de um aprofundamento quanto à própria relação entre as instâncias educativas voltadas para a infância, no sentido de explorar influências recíprocas (pré-escola sobre a escola e vice-versa)" (ROCHA, 1996, p.134-135). 
Considero esse ponto fundamental para o debate: problematizar os nexos entre a educação infantil e a escola de ensino fundamental, para além da sua estreita vinculação seqüencial no nível da educação básica, e pensar que a consolidação da especificidade de uma etapa educativa depende, também e não somente, da sua relação com a outra, ou, dito de outra forma, que a identidade nasce da diferenciação com o outro; nesse sentido não se pode abdicar do enfrentamento dessa questão. Vale perguntar, por exemplo: quais consensos a área de educação infantil já construiu sobre a natureza e especificidade das instituições educativas para as crianças pequenas? Que receios os pesquisadores visualizam na configuração da escola de ensino fundamental e que, desse modo, não recomendam para a educação infantil? Quais contribuições o ensino fundamental pode fornecer à educação infantil e vice-versa?

\section{Palavras Finais}

\section{Educação infantil e ensino fundamental - pode haver algo em comum?}

Avalio que há consenso entre os pesquisadores da área de educação infantil brasileira quanto à idéia de que as particularidades da etapa da educação infantil compreendem as ações indissociáveis de cuidar e educar, complementando os cuidados e educação realizados na família e pelo contexto sociofamiliar. Tem sido bem divulgada pela literatura especializada tal posição e com freqüência os trabalhos acadêmicos, as propostas nos sistemas educativos, os documentos normativos, têm reiterado tal perspectiva. De um lado, entende-se que isso configura uma incorporação conceitual que alimenta a identidade em construção da educação infantil. De outro, parece representar uma frágil e repetitiva "frase de efeito", que justifica práticas e propósitos os mais distintos e de procedências as mais variadas - teóricas e políticas.

Talvez um recurso necessário seja retomar algumas dessas posições já lançadas a fim de projetar luz naquilo que é meritório.

Mais uma vez retomo os Anais do I Simpósio Nacional de Educação Infantil (1994), e nele encontro a seguinte passagem: 
para que um programa ou política de educação infantil possa educar e cuidar de crianças pequenas, deve focar a criança como alvo central, mas não pode descurar das necessidades dos adultos envolvidos no processo: a família da criança e os profissionais que ali trabalham. Se necessidades de pais e adultos profissionais devem ser contempladas, as decisões para orientação dos programas não podem desconsiderar que são as necessidades da criança que devem orientar opções. (ROSEMBERG, 1994, p.155)

O fragmento acima aponta para o reconhecimento de que o processo de cuidado e educação é muito mais amplo que uma ação de atenção exclusiva às necessidades primárias da criança (como sono, alimentação, higiene do corpo), perspectiva usual, e envolve os sujeitos presentes na instituição educativa: a criança, a família da criança e o profissional que ali atua.

Outro conjunto de argumentos na defesa da utilização de tais conceitos na educação infantil pode-se encontrar em Cerisara, que informa que a insistência em manter os termos educar e cuidar vincula-se à trajetória histórica das creches e pré-escolas no Brasil, e que o exame do

histórico dessas instituições e as relações que estas têm estabelecido tanto com as famílias, quanto com as escolas permite perceber que quando se defendeu, e ainda hoje se defende, uma função pedagógica para as mesmas foi na direção da valorização das atividades ao ensino de alguma coisa, à transmissão de conhecimentos, muitas vezes reproduzindo ou antecipando as práticas condenadas pelas próprias escolas de ensino fundamental em que são valorizadas as atividades dirigidas, consideradas como pedagógicas. Essa interpretação reducionista do pedagógico, acabou por trazer para as creches e pré-escolas uma desvalorização das atividades ligadas ao cuidado das crianças pequenas. Essa dicotomização entre as atividades com um perfil mais escolar e as atividades de cuidado, revelam que ainda não está clara uma concepção de criança como sujeito de direitos, que necessita ser educada e cuidada, uma vez que ela depende dos adultos para sobreviver e também pelo fato de permanecer muitas vezes de 10 a 12 horas diárias na instituição de educação infantil. (CERISARA, 1999, p. 12-13) 
A pontuação feita por Cerisara remete à discussão da relação histórica da educação infantil com a escola e a instauração de práticas reducionistas, escolarizantes nas instituições para crianças pequenas, que desqualificam o trabalho de cuidar/educar e ao mesmo tempo supervalorizam, o que, em nome disso, se nomeia de pedagógico.

Compreendo e defendo a avaliação que Cerisara realiza, porém aproveito questões por ela trazidas para provocar outras reflexões. A primeira é sobre uma recorrência em textos e apresentações de trabalhos nos eventos da área de educação infantil quanto a uma espécie de "demonização da escola" e "vitimização da educação infantil"; ou seja, que muitos dos problemas que a educação infantil brasileira vem sofrendo relacionam-se com a incorporação de "práticas escolares", empregadas como sinônimo de propostas reducionistas, retrógradas, não comprometidas com a formação ampliada da criança, etc., e a comprovação de tais argumentos por vezes vem acompanhada das inúmeras estatísticas de fracasso escolar no Brasil como demonstrativo de que a escola não é modelo sequer para si. Incomoda-me a improvisação de práticas ligeiras, tarefeiras e disciplinarizadoras na educação infantil, no ensino fundamental, bem como em outras etapas, níveis e modalidades de educação, assim como a adoção de proposta pedagógica que exclua a diversidade de linguagens no campo da ciência, da arte, da mídia, e de perspectivas culturais discriminatórias de sexo, raça/etnia e idade.

Um dos elos entre a educação infantil e o ensino fundamental talvez seja um projeto de formação humana, formação para emancipação das crianças e dos adultos que nesses espaços atuam, aqui no sentido adorniano. ${ }^{12}$ Nessa perspectiva, estabelecer relação com a escola, construir projeto com ela, apropriar-se até de práticas escolares não significaria, necessariamente, ao meu juízo, um enquadramento limitador: o desafio estaria de estar junto sem ser igual! O que está em jogo é uma educação de qualidade, aqui entendida como inventiva, crítica, acolhedora, propositiva, provocativa, planejada, e isso a escola pode ser, mesmo que parcialmente, assim como as práticas de educação infantil também podem estar corroídas de improvisação, de espontaneísmos, de pobreza cultural. A questão da qualidade remete ao direito ao acesso e permanência à educação, direito que tem sido constantemente negado às crianças brasileiras, especialmente às de educação infantil. Tal constatação evidencia-se nos dados que apresento a seguir, fruto de uma pesquisa, em andamento, coordenada pela Universidade Federal do Paraná ${ }^{13}$ com dados de violações de direitos da criança e do adolescente registrados por Conselhos Tutelares de 36 municípios que incluem Curitiba e Região Metropolitana, Vale do Ribeira e Litoral do Paraná.

12 Adorno, T. Educação e Emancipação. Rio de Janeiro: Paz e Terra, 1995.

13 Pelo professor doutor Paulo Vinicius Baptista da Silva, do setor de Educação, a quem aproveito para agradecer pelos dados cedidos. 
No ano de 2006, os conselheiros tutelares dessas três regiões lançaram um total de 17.067 registros de violações de direitos no Sistema de Informação para a Infância e Adolescência (SIPIA). Nos cinco direitos fundamentais especificados pelo Estatuto da Criança e do Adolescente, computaram-se 1.399 $(8 \%)$ violações ao Direito à Vida e à Saúde; $2.880(17 \%)$ violações ao Direito à Liberdade, Respeito e Dignidade; 5.748 (34\%) violações ao Direito à Convivência Familiar e Comunitária; 450 (3\%) violações ao Direito à Profissionalização e Proteção no Trabalho; e 6.590 (38\%) violações ao Direito à Educação, Cultura Esporte e Lazer.

Na tabela 1 apresento os dados relativos às violações ao Direito à Educação, Cultura Esporte e Lazer, distribuídos pelas categorias que constam do SIPIA. Além do total de violações e respectivo percentual, foram inseridos na última coluna os resultados relativos ao Estado/Setor Público quando anotado como agente violador do respectivo direito (o sistema trabalha com cinco alternativas de agentes violadores, mas para o fim específico desta análise foi selecionado somente um).

TABELA 1 - VIOLAÇÕES AO DIREITO À EDUCAÇÃO, CULTURA, ESPORTE E LAZER E AGENTE VIOLADOR ESTADO, ANOTADAS NO SIPIA EM 2006, EM 36 MUNICÍPIOS DO PARANÁ

\begin{tabular}{ccc}
\hline VIOLAÇÕES & $\begin{array}{c}\text { AGENTE } \\
\text { TOTAL DE } \\
\text { VIOLAÇÕES }\end{array}$ & $\begin{array}{c}\text { ESTADOLORETOR } \\
\text { PÚBLICO }\end{array}$ \\
\hline $\begin{array}{c}\text { Impedimento de acesso ao ensino fundamental } \\
\text { Impedimento de permanência no sistema } \\
\text { Ausência/Impedimento de acesso à creche/ } \\
\text { pré-escola } \\
\text { das }\end{array}$ & $1831(28 \%)$ & $1424(22 \%)$ \\
Ausência de condições educacionais adequa- & $3266(50 \%)$ & $3067(4 \%)$ \\
das & $210(3 \%)$ & $74(1 \%)$
\end{tabular}


Ausência/impossibilidade de uso de equipamento para cultura/esporte/lazer

Atos atentatórios ao exercício da cidadania

Impedimento de acesso ao ensino médio
$71(1 \%)$

$775(12 \%)$

$217(3 \%)$
$52(1 \%)$

$153(2 \%)$

$172(3 \%)$

Total

$6590(100 \%)$

$5006(76 \%)$

FONTE: Tabulações para pesquisa do Conselho Estadual de Defesa dos Direitos da Criança e do Adolescente (CEDCA) e da UFPR

Como fica evidente pelos dados apresentados, a violação ao Direito à Educação, Cultura, Esporte e Lazer foi a mais freqüentemente anotada por conselheiros tutelares (6.590 casos), em 2006. A ausência ou impedimento de acesso à creche ou pré-escola corresponde à metade do total de tais violações. Ou seja, a falta de vagas na educação infantil corresponde à violação de Direito mais freqüente no trabalho de atendimento direto à população, realizado pelos Conselhos Tutelares. A análise dos resultados relativos ao agente violador reforça que o problema consiste na ausência de vagas, pois o poder público é apontado como responsável pela violação na maioria absoluta dos casos. Os dados lançados pelos conselheiros tutelares, que derivam de seus atendimentos à população, podem ser tomados como indicadores da fragilidade na prática cotidiana de efetivação dos dispositivos constitucionais que asseguram os direitos de toda criança de zero a seis anos (art.208, inciso IV), e também o direito dos trabalhadores à assistência gratuita aos filhos e dependentes desde o nascimento até os seis anos de idade em creches e pré-escolas (art. $7^{\circ}$, inciso XXV), e o dever do Estado para com essas crianças e suas famílias (art. 208, inciso IV).

Entendo que a consolidação da identidade da educação infantil como campo próprio, dotado de valor social e político-educativo, se faça conjuntamente na luta pela ampliação da oferta da educação infantil de qualidade, mas também na incansável vigília do cumprimento da lei em favor dos pequenos. 


\section{REFERÊNCIAS}

ADORNO, Theodor. Educação e emancipação. Rio de Janeiro: Paz e Terra, 1995.

BARRETO, Angela Maria Rabelo F. A formação do profissional de educação infantil. In: SIMPÓSIO NACIONAL DE EDUCAÇÃO INFANTIL: CONFERÊNCIA NACIONAL PARA TODOS, 1., 1994. Anais... Brasília: MEC/SEF/DPE/COEDI, 1994. p. 124-128.

BRASIL. Constituição da República Federativa do Brasil. São Paulo: Saraiva, 1998.

BRASIL. Lei de Diretrizes e Bases da Educação Nacional - Lei n. 9.394/96.

BRASIL. Ministério da Educação e Cultura. Recomendações. In: SIMPÓSIO NACIONAL DE EDUCAÇÃO INFANTIL: CONFERÊNCIA NACIONAL DE EDUCAÇÃO PARA TODOS, 1., Brasília, 1994. Anais... Brasília: MEC/SEF/DPE/ COEDI, 1994. p. 170-173.

BRASIL. Ministério da Educação e Cultura. Critérios para um atendimento em creches que respeite os direitos fundamentais das crianças/Maria Malta Campos e Fulvia Rosemberg. Brasília: MEC/SEF/DEP/COEDI, 1997.

CERISARA, Ana Beatriz. Educar e cuidar: por onde anda a educação infantil? Perspectiva, Florianópolis, v. 17, n. especial, p. 11-21, jul./dez. 1999.

CRAIDY, Carmem Maria. A política de educação infantil no contexto da política da infância no Brasil. In: SIMPÓSIO NACIONAL DE EDUCAÇÃO INFANTIL: CONFERÊNCIA NACIONAL DE EDUCAÇÃO PARA TODOS, 1., Brasília, 1994. Anais... Brasília: MEC/SEF/DPE/COEDI, 1994. p. 18-21.

CURY, Carlos Roberto Jamil. A educação básica no Brasil. Educação \& Sociedade, Campinas, v. 23, n. 80, p. 169-201, set. 2002.

. Educação escolar e educação no lar: espaços de uma polêmica. Educação \& Sociedade, Campinas, v. 27, n. 96 - especial, p. 667-688, out. 2006.

MIEIB. Educação infantil: construindo presente. Campo Grande: UFMS, 2002.

PALHARES, Marina Silveira; MARTINEZ, Cláudia Maria Simões. A educação infantil: uma questão para o debate. In: FARIA, Ana L. G. de; PLHARES, Marina S. (Org.). Educação infantil Pós-LDB: rumos e desafios. Campinas: Autores Associados/ FE/Unicamp; São Carlos: Editora da UFSCar; Florianópolis: Editora da UFSC, 2003. (Coleção Polêmicas do Nosso Tempo, n. 62). 
PARANÁ. Decreto n. 479, de 10 de dezembro de 1907. Regulamento da Instrução Pública do Estado do Paraná, a partir de 16 de janeiro de 1908.

PARANÁ. Decreto n. 510, de 15 de setembro de 1909. Regulamento Orgânico do Ensino Público do Estado.

ROCHA, Eloísa Acires Candal. A pesquisa em educação infantil no Brasil: trajetória recente e perspectiva de consolidação de uma pedagogia da educação infantil. Florianópolis: UFSC, 1999.

ROSEMBERG, Fúlvia. Literatura infantil e ideologia. São Paulo: Global, 1985.

. O movimento de mulheres e a abertura política no Brasil: o caso da creche - 1984. In: ROSEMBERG, F. (Org.). Creche. São Paulo: Cortez/Fundação Carlos Chagas, 1989. p. 90-103.

. Qualidade na educação infantil: uma perspectiva internacional. In: SIMPÓSIO NACIONAL DE EDUCAÇÃO INFANTIL: CONFERÊNCIA NACIONAL PARA TODOS, 1., Brasília, 1994. Anais... Brasília: MEC/SEF/DPE/COEDI, 1994. p. 154156.

SEBASTIANI, Márcia Teixeira. Educação infantil: o desafio da qualidade - um estudo da rede municipal de creches em Curitiba - 1989 a 1992. Tese de Doutorado, Faculdade de Educação da UNICAMP, 1996.

SOUZA, Gizele de. Instrução, o talher para o banquete da civilização: cultura escolar dos jardins-de-infância e grupos escolares no Paraná, 1900-1929. Tese de Doutorado - Programa de Estudos Pós-Graduados em Educação: História, Política, Sociedade, PUC/SP, 2004.

Texto recebido em 16 set. 2007

Texto aprovado em 19 nov. 2007 